\title{
Малый бизнес и несырьевой экспорт в Кузбассе ${ }^{1}$
}

И.А. КУДРЯШОВА, доктор экономических наук. E-mail: kudrina2007@mail.ru Е.Н. БАЛАГАНСКАЯ, кандидат экономических наук.

E-mail: balaganskaya2004@mail.ru

л.И. ВОРОНИНА, кандидат экономических наук,

Российский экономический университет имени Г. В. Плеханова,

Кемеровский институт (филиал), Кемерово. E-mail: larisa_voronina@mail.ru

В статье представлены результаты исследования динамики, товарной и географической структуры экспорта Кемеровской области в свете общероссийских сравнений за последние пять лет. Отдельное внимание уделено анализу экспорта несырьевых товаров как фактора качественного улучшения структуры внешней торговли и укрепления позиций региона на внешних рынках. Полученные выводы свидетельствуют о том, что динамика несырьевого экспорта Кузбасса не только совпадает с общероссийской тенденцией к росту, но и опережает ее по некоторым группам товаров на фоне сохранения сырьевой ориентации. Доказан тезис о необходимости расширения несырьевого неэнергетического экспорта как фактора снижения “экологоемкости» региональной экономики, развития малого и среднего предпринимательства и снижения бизнес-миграции из Кемеровской области. Обоснована необходимость создания в Кемеровской области Регионального центра поддержки экспорта.

Ключевые слова: Экспортный потенциал региона; внешняя торговля; несырьевой неэнергетический экспорт; «экологоемкость» регионального экспорта; бизнес-миграция МСп

Для любого региона страны развитие внешнеэкономических связей является одним из важнейших видов деятельности. Кемеровская область исторически принадлежит к регионам с экспортной направленностью экономики. По данным Федеральной таможенной службы России, в 2017 г. по объему экспорта (13872,3 млн долл.) она уступала только Москве (148623,1 млн долл.), Санкт-Петербургу (21 764,7 млн долл.) и Ханты-Мансийскому АО (14498,9 млн долл.).

\section{Экспорт в России}

Общий объем национального экспорта за 2013-2017 гг. уменьшился почти в 1,5 раза - с 526,9 до 357 млрд долл., главным

\footnotetext{
${ }^{1}$ Статья подготовлена в рамках выполнения научно-исследовательской работы по теме: «Эколого-экономический механизм функционирования минерально-сырьевых кластеров для обеспечения устойчивого развития добывающих регионов (приказ ФГБОУ ВО «Российский экономический университет им. Г. В. Плеханова» № 637 от 08.05.2018)».
} 
образом за счет сокращения вывоза минеральных продуктов вследствие неблагоприятной конъюнктуры и высоких колебаний цен на глобальном рынке. Так, по группе топливно-энергетических товаров и металлов экспорт за пять лет снизился в 1,7 раза. При этом по товарной группе «машины и оборудование» снижение составило всего 2,5\% (с 28,9 до 28,2 млрд долл.), а по продовольственным и сельскохозяйственным товарам произошел рост на 25\% (с 16,3 до 20,5 млрд долл.) (табл. 1).

\section{Таблица 1. Товарная структура экспорта России за 2013-2017 гг., млрд долл.}

\begin{tabular}{|l|c|c|c|c|c|c|c|c|c|c|}
\hline \multirow{2}{*}{ Показатель } & \multicolumn{2}{|c|}{$\mathbf{2 0 1 3}$} & \multicolumn{2}{|c|}{$\mathbf{2 0 1 4}$} & \multicolumn{2}{|c|}{$\mathbf{2 0 1 5}$} & \multicolumn{2}{|c|}{$\mathbf{2 0 1 6}$} & \multicolumn{2}{|c|}{$\mathbf{2 0 1 7}$} \\
\cline { 2 - 12 } & Bсего & $\begin{array}{c}\text { Доля } \\
\text { (\%) }\end{array}$ & Всего & $\begin{array}{c}\text { Доля } \\
\text { (\%) }\end{array}$ & Всего & $\begin{array}{c}\text { Доля } \\
\text { (\%) }\end{array}$ & Всего & $\begin{array}{c}\text { Доля } \\
\text { (\%) }\end{array}$ & Bсего & $\begin{array}{c}\text { Доля } \\
\text { (\%) }\end{array}$ \\
\hline ВСЕго & 527,2 & 100 & 497,7 & 100 & 343,6 & 100 & 285,6 & 100 & 357,0 & 100 \\
\hline $\begin{array}{l}\text { Продовольственные } \\
\text { товары и с/х }\end{array}$ & 16,3 & 3,0 & 18,9 & 3,7 & 16,3 & 4,7 & 17,1 & 6,0 & 20,5 & 5,7 \\
\hline $\begin{array}{l}\text { Минеральные про- } \\
\text { дукты, в том числе: }\end{array}$ & 377,1 & 71,5 & 350,9 & 70,5 & 219,2 & 63,7 & 169,1 & 59,2 & 216,1 & 60,5 \\
\hline $\begin{array}{l}\text { Топливно-энергети- } \\
\text { ческие товары }\end{array}$ & 372,1 & 70,5 & 346,1 & 69,5 & 216,2 & 62,9 & 166,1 & 58,1 & 212,0 & 59,3 \\
\hline $\begin{array}{l}\text { Продукция химиче- } \\
\text { ской промышлен- } \\
\text { ности, каучук }\end{array}$ & 30,8 & 5,8 & 29,2 & 5,8 & 25,5 & 7,4 & 20,7 & 7,3 & 23,8 & 6,7 \\
\hline $\begin{array}{l}\text { Кожевенное сырье, } \\
\text { пушнина }\end{array}$ & 0,5 & 0,09 & 0,3 & 0,06 & 0,3 & 0,08 & 0,2 & 0,1 & 0,2 & 0,1 \\
\hline Древесина & 10,9 & 1,0 & 11,7 & 2,3 & 9,8 & 2,8 & 9,8 & 3,4 & 11,8 & 3,3 \\
\hline Текстиль & 1,0 & 0,1 & 1,1 & 0,2 & 0,8 & 0,2 & 1,0 & 0,3 & 1,1 & 0,3 \\
\hline $\begin{array}{l}\text { Драгоценные камни } \\
\text { и металлы }\end{array}$ & 14,3 & 2,7 & 11,9 & 2,3 & 7,9 & 2,2 & 8,9 & 3,1 & 10,9 & 3,0 \\
\hline Металлы & 40,9 & 7,7 & 40,4 & 8,1 & 32,9 & 9,5 & 28,8 & 10,1 & 37,0 & 10,4 \\
\hline $\begin{array}{l}\text { Машины, оборудо- } \\
\text { вание }\end{array}$ & 28,9 & 5,4 & 26,4 & 5,3 & 25,4 & 7,3 & 24,4 & 8,5 & 28,2 & 7,9 \\
\hline Другие товары & 6,5 & 1,2 & 6,9 & 1,3 & 5,5 & 1,6 & 5,6 & 2,0 & 7,4 & 2,1 \\
\hline
\end{tabular}

Источник табл. 1, 3: рассчитано авторами по данным Федеральной таможенной службы России [Эл. ресурc]. URL: www.stat.customs.ru (дата обращения: 13.07.2018)..

Снижение экспорта наблюдалось на протяжении почти пять лет, и лишь в 2017 г. негативную динамику удалось переломить. Внешнеторговый оборот России в этот год увеличился на 25\%, до 584 млрд долл.; аналогичную динамику показали экспорт и импорт, составившие 357 и 227 млрд долл., соответственно. 
В 2018 г. стоимостные показатели поставок российских товаров за рубеж впервые превысили уровень докризисного 2013 г.

Основная причина высоких темпов роста российского экспорта - увеличение мировых цен на углеводороды (в январе - июле 2017 г. цена нефти марки Urals была на 29,8\% выше, чем годом ранее), импорта - укрепление рубля (по данным Банка России, индекс реального курса рубля к доллару США в январе - июле вырос на 21,3\% в годовом выражении).

Несмотря на некоторое сокращение поставок углеводородов, структура российского экспорта все еще сохраняет ярко выраженную топливно-сырьевую направленность (табл. 1). Второй по значимости статьей является продукция черной и цветной металлургии. Из других товарных групп, значимых для национального экспорта, можно выделить продукцию химической промышленности (в 2017 г. рост в ценовом выражении составил $9,3 \%$ и $21,4 \%$ в страны дальнего зарубежья и СНГ соответственно, при этом физические объемы поставок в СНГ выросли на $9,4 \%$, а в страны дальнего зарубежья снизились на $0,2 \%)^{2}$; машины и оборудование (экспорт за год увеличился на 7,1\%). В этой группе наибольшее влияние на динамику экспорта оказывают зарубежные поставки частей ядерных реакторов и тепловыделяющих элементов (основные импортеры - Китай, Болгария, Чехия и Украина), а также турбореактивных и турбовинтовых двигателей. Кроме того, хорошие темпы роста (около 30\%) сохраняет экспорт легковых автомобилей.

Продовольственные товары и сырье для их производства замыкают пятерку лидеров по доле в товарной структуре экспорта. В 2017 г. экспорт продукции вырос как в стоимостном, так и в физическом выражении: прирост в страны дальнего зарубежья составил $18,5 \%$ и $13,7 \%$, а в страны СНГ $-20,4 \%$ и 9,2\% соответственно.

Оценивая географическую структуру внешней торговли, отметим, что традиционно основное место в ней принадлежит Европейскому союзу (42\% в 2017 г., 42,8\% в 2016 г.). Затем идут страны АТЭС, постепенно увеличивающие свою долю $(31,0 \%$ в 2017 г. против 30,0\% 2016 г.) и СНГ (12,0\% в 2017 г. и 12,1\% в 2016 г.). Отметим также, что за 2017 г. Россия увеличила свое

${ }^{2}$ Таможенная статистика внешней торговли ФТС России [Эл. ресурc]. URL: www. stat.customs.ru (дата обращения: 13.07.2018). 
присутствие в странах ЕАЭС (экспорт вырос с 8,3\% до 9,0\% в общем объеме наших зарубежных поставок).

\section{Экспорт в Кузбассе}

Структура внешнеторговых поставок Кемеровской области, как и в целом по РФ, носит в большей степени сырьевой характер (табл. 2). При этом тот факт, что предприятия Кузбасса экспортируют более 100 наименований продукции в страны ближнего и дальнего зарубежья ${ }^{3}$, по нашему мнению, указывает на потенциальные возможности развития несырьевого экспорта.

\section{Таблица 2. Результаты внешней торговли Кемеровской области} за 2013-2017 гг., млн долл.

\begin{tabular}{|l|c|c|c|c|c|}
\hline \multicolumn{1}{|c|}{ Показатель } & $\mathbf{2 0 1 3}$ & $\mathbf{2 0 1 4}$ & $\mathbf{2 0 1 5}$ & $\mathbf{2 0 1 6}$ & $\mathbf{2 0 1 7}$ \\
\hline ВСЕГО & 12947,4 & 12926,1 & 10228,0 & 10094,4 & 14517,7 \\
\hline $\begin{array}{l}\text { В том числе: } \\
\text { Со странами СНГ }\end{array}$ & 1159,2 & 1179,9 & 1075,7 & 1267,9 & 1726,7 \\
\hline Со странами дальнего зарубежья & 11788,2 & 11746,2 & 9152,3 & 8826,5 & 12791,0 \\
\hline ЭКСПОРТ & 12284,7 & 12397,6 & 9822,3 & 9593,2 & 13872,3 \\
\hline $\begin{array}{l}\text { В том числе: } \\
\text { со странами СНГ }\end{array}$ & 1098,8 & 1161,4 & 1065,1 & 1211,3 & 1642,1 \\
\hline Со странами дальнего зарубежья & 11185,9 & 11236,2 & 8757,2 & 8381,9 & 12230,2 \\
\hline ИМПОРТ & 662,7 & 528,5 & 405,7 & 501,2 & 645,4 \\
\hline $\begin{array}{l}\text { В том числе: } \\
\text { со странами СНГ }\end{array}$ & 60,4 & 18,5 & 10,7 & 56,7 & 84,6 \\
\hline со странами дальнего зарубежья & 602,3 & 510,0 & 395,0 & 444,5 & 560,8 \\
\hline
\end{tabular}

Источник: составлено авторами на основе данных Кемеровской таможни.

В отличие от России в целом, экспортные поставки из Кемеровской области в 2013-2017 гг. не только не сократились, но даже выросли на 13\% (с 12,3 до 13,9 млрд долл.). Лишь в 2016 г. было отмечено падение на 22\%. Отметим, что в тот же год в регионе наметилась активизация экспортной и импортной деятельности со странами СНГ (рост на 13,7\% и 430\%, соответственно). Уже в 2017 г. темпы роста экспорта и импорта в регионе достигли 44,6\% и 28,8\% соответственно, а стоимостные показатели превысили уровень 2013 г.

\footnotetext{
${ }^{3}$ Итоги внешней торговли субъектов Российской Федерации [Эл. pecypc]. URL: http://www.customs.ru/index2.php?option=com_content\&view=article\&id=26282\&Item $\mathrm{id}=2095$ (дата обращения: 08.08.2018).
} 
По объемам экспорта в 2017 г. Кемеровская область занимает первое место в Сибирском федеральном округе (42\%) и четвертое - в РФ $(3,8 \%)$, обеспечивая экстравертный характер региональной экономики: экспорт Кемеровской области в 24 раза превалирует над импортом и составляет 96\% в структуре внешнеторгового товарооборота. Для сравнения: в 2013 г. Кемеровская область занимала 8-е место по объемам экспорта в РФ 4 .

Необходимо отметить, что данный факт не дает полного основания говорить о прорывном движении Кузбасса вперед за последние пять лет, поскольку на впечатляющий рост стоимостных показателей повлияло внедрение перспективных таможенных технологий [Воронина, 2016]. В частности, благодаря технологии удаленного выпуска деклараций, в Кемеровской таможне проходят оформление участники ВЭД из нескольких других регионов, что может приводить к завышению экспортных возможностей кузбасских производителей 5 .

Преобладающими статьями регионального экспорта в течение многих лет является продукция металлургии и топливноэнергетического комплекса. На их долю в 2017 г. пришлось $87,3 \%$ стоимостного экспорта в регионе, что свидетельствует о сырьевой специализации Кузбасса даже более глубокой, чем у России в целом (70\%). На долю химической промышленности (в основном это удобрения и продукция органического синтеза) в структуре регионального экспорта приходится 9,4\% (у РФ - 6,7\%). Доля пищевой и прочей продукции составляет $3,3 \%$ (у РФ - 5,7\%) (табл. 3).

В исследуемый период в Кемеровской области наблюдались рост производства в промышленности и улучшение финансового положения ряда предприятий, обусловленные главным образом общеэкономическими факторами: развитием импортозамещения в обрабатывающих отраслях, активизацией экспорта некоторых видов товаров в условиях благоприятной внешнеэкономической конъюнктуры, в некоторых случаях - оказанием государственной

\footnotetext{
4 Экспорт регионов. Аналитический портал РЭЦ [Эл. pecypc]. URL: https://regionstat. exportcenter.ru/regions/map/ (дата обращения: 08.08.2018).

${ }^{5}$ Количество участников ВЭД в зоне ответственности Кемеровской таможни увеличилось на 27\% [Эл. peсурс]. URL: http://stu.customs.ru/index.php?option=com content\&view=article\&id=17629: $-27 \&$ catid=4: news\&Itemid=88 (дата обращения: 10.08.2018).
} 
поддержки благодаря размещению на предприятиях регионального заказа и оказанию господдержки (выделение бюджетных ссуд, предоставление налоговых льгот).

\section{Таблица 3. Товарная структура экспорта Кемеровской области за 2014-2017 гг., млн долл.}

\begin{tabular}{|l|c|c|c|c|}
\hline \multicolumn{1}{|c|}{ Наименование товара } & $\mathbf{2 0 1 4}$ & $\mathbf{2 0 1 5}$ & $\mathbf{2 0 1 6}$ & $\mathbf{2 0 1 7}$ \\
\hline $\begin{array}{l}\text { ВСЕгО } \\
\text { В том числе: }\end{array}$ & 12397,6 & 9822,3 & 9593,2 & 13872,3 \\
\hline Уголь каменный & 8898,9 & 6960,7 & 6798,4 & 9723,1 \\
\hline $\begin{array}{l}\text { Полуфабрикаты из железа или неле- } \\
\text { гированной стали }\end{array}$ & 1264,7 & 742,0 & 837,4 & 1335,1 \\
\hline $\begin{array}{l}\text { Нефть и нефтепродукты, полученные } \\
\text { из битуминных пород, кроме сырых }\end{array}$ & 804,9 & 797,9 & 536,9 & 948,4 \\
\hline Кокс и полукокс из каменного угля & 133,2 & 111,0 & 75,2 & 314,2 \\
\hline Ферросплавы & 407,7 & 334,5 & 291,3 & 247,6 \\
\hline Соединения гетероциклические & 191,1 & 157,5 & 125,4 & 212,9 \\
\hline Алюминий необработанный & 214,2 & 274,9 & 172,0 & 193,4 \\
\hline $\begin{array}{l}\text { Прутки из железа или нелегированной } \\
\text { стали прочие }\end{array}$ & 51,8 & 56,4 & 82,3 & 159,8 \\
\hline $\begin{array}{l}\text { Удобрения минеральные или химиче- } \\
\text { ские, азотные }\end{array}$ & 191,6 & 139,0 & 188,3 & 156,2 \\
\hline $\begin{array}{l}\text { Шоколад и прочие готовые пищевые } \\
\text { продукты, содержащие какао }\end{array}$ & - & - & 65,9 & 81,6 \\
\hline $\begin{array}{l}\text { Хлеб и пр. хлебобулочные и мучные } \\
\text { кондитерские изделия }\end{array}$ & - & 8,5 & 53,7 & 64,7 \\
\hline Прочие & 239,5 & 239,9 & 366,4 & 435,3 \\
\hline
\end{tabular}

Согласно классификации, разработанной Российским экспортным центром совместно с Всероссийской академией внешней торговли, вся экспортная продукция подразделяется на сырьевую и несырьевую. Последняя представлена в трех категориях: нижних, средних и верхних переделов ${ }^{6}$.

Рассматривая товарную структуру несырьевого неэнергетического экспорта Кемеровской области через призму этой классификации, отметим, что в 2017 г. наблюдается превалирование сегмента продукции нижнего передела $(68,8 \%)$, средний передел (промежуточные продукты достаточно глубокой степени переработки) занимает долю в 15,9\%, продукция верхнего передела

\footnotetext{
${ }^{6}$ Классификация экспортных товаров. Российский экспортный центр [Эл. ресурс]. URL: https://www.exportcenter.ru/international_markets/classification/ (дата обращения: 08.08.2018).
} 
(готовые товары) - 15,1\%. Последняя категория представлена в основном продукцией агропромышленного комплекса, пищевой отрасли и машиностроения.

Всего же, по данным РЭЦ, в структуре экспорта Кемеровской области в 2017 г. доля несырьевого неэнергетического экспорта составила 20,72\%7 . (Для сравнения: в целом по России - 36,2\% в денежном выражении - 130 млрд долл.).

Ярко выраженная и со временем усиливающаяся сырьевая направленность регионального экспорта обусловлена как факторами размещения производства, так и проводимой в последние 20 лет политикой приоритетной поддержки традиционных для Кузбасса отраслей в лице крупнейших угольных, металлургических и химических предприятий (они же крупнейшие экспортеры) (табл. 4).

\section{Таблица 4. Структура экспорта Кемеровской области (по степени переработки) в 2013-2017 гг., \%/млрд долл.}

\begin{tabular}{|l|c|c|c|c|c|c|}
\hline \multicolumn{1}{|c|}{ Экспорт } & $\mathbf{2 0 1 3}$ & $\mathbf{2 0 1 4}$ & $\mathbf{2 0 1 5}$ & $\mathbf{2 0 1 6}$ & $\mathbf{2 0 1 7}$ & $\begin{array}{c}\text { Темп роста } \\
\text { в 2017 г. } \\
\text { к 2013 r. }\end{array}$ \\
\hline Сырьевой & $71,6 / 9,6$ & $70,2 / 8,9$ & $67,9 / 7,0$ & $70,8 / 6,8$ & $70,1 / 9,7$ & $97,9 / 101,0$ \\
\hline $\begin{array}{l}\text { Несырьевой } \\
\text { неэнергетический }\end{array}$ & $24,6 / 3,1$ & $21,8 / 2,7$ & $22,3 / 2,3$ & $22,6 / 2,1$ & $20,7 / 2,8$ & $84,1 / 90,3$ \\
\hline $\begin{array}{l}\text { Несырьевой } \\
\text { энергетический }\end{array}$ & $3,6 / 0,4$ & $7,8 / 1,0$ & $9,6 / 1,0$ & $6,5 / 0,6$ & $9,1 / 1,2$ & $252,7 / 300,0$ \\
\hline
\end{tabular}

Источник: составлено авторами на основе данных РЭЦ.

При этом нельзя не отметить, что в стоимостном выражении несырьевой сегмент экспорта проявляет очевидную тенденцию к росту. Значимую долю в нем составляют продукция нефтепереработки, угольный кокс и электроэнергия. Кроме того, можно выделить опережающий (на 15-20\% ежегодно) рост объемов вывоза сельхозпродукции. По этому показателю Кемеровская область следует полностью в русле общероссийской динамики. Основными экспортируемыми группами товаров в этом сегменте в 2017 г. были шоколадные, мучные кондитерские изделия, хлеб,

\footnotetext{
7 Экспорт регионов. Аналитический портал РЭЦ [Эл. pecypc]. URL: https:/regionstat. exportcenter.ru/structure/piechart/ (дата обращения: 08.08.2018).

${ }^{8}$ Российский несырьевой экспорт за шесть лет должен удвоиться до 250 млрд долл. в год. Информационное агентство России TACС [Эл. pecypc]. URL: http://tass.ru/ ekonomika/4998573 (дата обращения: 08.08.2018).
} 
плодоовощная продукция, крепкие спиртные напитки, сахаристые кондитерские изделия. Экспорт сои, рапса, мороженого также показывает положительную динамику.

Анализ сложившейся экспортной модели Кемеровской области с гипертрофированной долей сырьевого экспорта и невысоким удельным весом продукции верхнего передела позволяет говорить о неустойчивом характере функционирования экономики региона, уязвимой от колебаний мировой конъюнктуры и внешнеполитических условий.

Наряду с этим следует отметить и противоречивость государственной политики в отношении региональных экспортеров. Усиление экспортной направленности региона не приводит к увеличению поступлений в региональный и местные бюджеты. Структура отчислений по подоходному налогу, налогу на прибыль, налогу на добавленную стоимость и без того складывается не в пользу регионов, а освобождение экспортной выручки от НДС, предоставляемое в рамках государственной политики стимулирования экспортеров, лишь усугубляет эту проблему.

В итоге нарастание экспортных потоков из Кузбасса и соответствующий рост таможенных сборов и платежей, ежегодно в полном объеме направляемых в федеральный бюджет, не приводят к улучшению общественного благосостояния региона. Их следствием становятся выкачивание природно-сырьевых ресурсов и ухудшение эколого-экономических характеристик. Рост «экологоемкости» регионального экспорта создает долгосрочные угрозы устойчивому развитию территории.

И тем не менее следует отметить, что, несмотря на внутренние трудности и противоречия, а также сильную зависимость от колебания мировых цен на сырье, экспортная деятельность на протяжении всего рассматриваемого периода оказывала важное стимулирующее влияние на развитие региональной экономики, являясь своеобразным ее локомотивом, и внесла существенный вклад в преодоление последствий кризиса 2014 г., вызванного введением санкций со стороны зарубежных стран. Это верно и для России в целом.

\section{Перспективы регионального экспорта}

На изменение стоимостных объемов экспорта влияют главным образом четыре фактора: сокращение или увеличение физического 
объема отгрузок, динамика цен на экспортные товары, изменение географии поставок, структурные сдвиги в экспорте. Рассмотрим возможности каждого из перечисленных факторов с целью оптимизации экспортной деятельности региона.

Потенциал дальнейшего увеличения сырьевых поставок за рубеж в среднесрочной перспективе, по всей видимости, исчерпан. Многие предприятия работают с полной производственной загрузкой и больше экспортировать не могут.

Рассчитывать на рост мировых цен на уголь не приходится из-за возросшей конкуренции на глобальном рынке и невозможности влияния на цены со стороны производителей. Кроме того, логично предположить, что благоприятная для России мировая конъюнктура рано или поздно может ухудшиться, что неизбежно приведет к падению экспортных доходов в угольной отрасли.

Возможности оптимизации географии экспорта, с одной стороны, затруднены из-за возрастания санкционного воздействия в отношении России. С другой - поиск перспективных растущих рынков (например, китайского, индийского и др.), безусловно, является актуальным направлением для российских и региональных поставщиков.

И все же, на наш взгляд, четвертый фактор - изменение структуры экспорта региона (в первую очередь - за счет увеличения доли несырьевой продукции) - способен оказать наибольшее влияние на результаты экспортной деятельности. В этой связи поиск новых направлений развития экономики Кузбасса представляется наиболее естественным и необходимым выходом из сложившейся ситуации.

В «майских» указах Президента была поставлена задача двукратного увеличения поставок несырьевой неэнергетической продукции на внешние рынки за ближайшие шесть лет и повышения доли малого и среднего бизнеса в экспорте до 10\% (сегодня 6\%). Для ее выполнения требуется создание эффективной системы развития экспортного потенциала малых и средних предприятий (МСП), с учетом специфики структуры экономики региона, а также внешних и внутренних рисков 9 .

\footnotetext{
${ }^{9} \mathrm{O}$ мерах по развитию системы поддержки экспорта несырьевых товаров» / Министерство экономического развития РФ [Эл. pecypc]. URL: http://www.rusexporter.ru/
} 
Между тем в Кемеровской области доля малого бизнеса весьма незначительна не только в стоимостных объемах экспорта, но и в общем количестве участников внешнеэкономической деятельности. По оценкам авторов, в 1 квартале 2018 г. она находилась на уровне 5-7\% (всего 15-20 предприятий). Эффективной поддержки их экспортной активности в регионе до сих пор не создано.

Небольшому предприятию, впервые выходящему на зарубежный рынок, довольно сложно самостоятельно пройти все стадии организации экспортной деятельности - от подготовки продукции, выработки стратегии выхода на внешний рынок, сертификации, маркировки, упаковки, соответствующих требованиям импортирующей страны, до поиска сбытовых партнеров за рубежом, оформления валютного контракта, страховки и т.д.

Для того чтобы помочь предприятиям решить эти и множество других проблем, со стороны региональных властей, институтов развития, финансовых организаций требуется комплексный подход, создание эффективной системы поддержки на всех этапах внешнеэкономической деятельности [Мосейко, 2012]. Те регионы, которые уделяют этому достаточно внимания, добиваются порой впечатляющих результатов. Как показал сравнительный анализ по СФО, в регионах с развитой инфраструктурой поддержки экспорта, широким спектром оказываемых услуг МСП доля несырьевой продукции в структуре экспорта значительно выше. Например, по данным РЭЦ, доля несырьевых неэнергетических товаров в экспорте Алтайского края составляет 56\%, Красноярского - 89\%, Новосибирской области $-61 \%$, Томской $-75 \%$. В этих регионах уже много лет осуществляется системная поддержка экспорта МСП.

В Кемеровской области до сих пор не создан Региональный центр поддержки экспорта, нет представительства Российского экспортного центра (в отличие от соседних регионов СФО), большинство инструментов государственной поддержки внешнеэкономической деятельности на практике недоступны. В целях активизации экспорта МСП региона необходимо использование таких хорошо зарекомендовавших себя инструментов, как проведение «таможенного сопровождения» экспортной сделки малого бизнеса, повышение доступности финансовых продуктов для экспортеров из числа малого бизнеса, субсидирование процентной ставки по кредитам для малого бизнеса, экспортирующего 
продукцию, предэкспортное кредитование малого бизнеса, создание новых продуктов финансовой, гарантийной и страховой поддержки экспорта МСП, субсидирование расходов, связанных с участием в бизнес-миссиях, оформлением разрешительной документации, продвижением на интернет-площадках и т.п.

По мнению авторов, развитие малого и среднего предпринимательства в регионе напрямую связано не только с возможностями расширения несырьевого неэнергетического экспорта, но и может выступать фактором снижения бизнес-миграции из Кемеровской области.

Эта проблема приобрела в последние годы особую остроту. Мало того, что с каждым годом растет число выезжающих из Кемеровской области на постоянное место жительства в другие субъекты РФ. В последние три-четыре года заметно активизировалась бизнес-миграция - регистрация бизнеса из Кузбасса в Новосибирской, Томской областях, Красноярском, Алтайском краях, а также в Москве, Санкт-Петербурге, Краснодаре. По мнению авторов, причины такого поведения бизнесменов можно разделить на две основные группы: административные и экономические. К первой относятся рост административного давления на малый бизнес со стороны контролирующих и правоохранительных органов, нередко - предвзятое отношение со стороны налоговой службы, перегибы бескомпромиссной борьбы с фирмами-однодневками, порой приводящие к остановке производства и банкротству [Потапова, 2018]. Ко второй - сокращение внутреннего рынка, падение уровня доходов населения, стремление оптимизировать растущую налоговую нагрузку, повысить показатели эффективности предприятия, рентабельность бизнеса и расширения рынка сбыта.

К сожалению, бизнес-миграция носит необратимый характер: никто из уехавших, как правило, не возвращается, хотя в Кемеровской области в последнее время проводится планомерная работа по улучшению инвестиционного климата, созданию благоприятных условий для бизнеса. Власти подчеркивают свое намерение наладить с ним «открытый диалог» и т.д. Однако существенных изменений в динамике бизнес-миграции пока не наблюдается [Колыханов, Балаганская, 2018]. 
Таким образом, преодоление сырьевой направленности кузбасского экспорта требует расширения круга участников внешнеэкономической деятельности, в первую очередь - за счет малых и средних предприятий. Наращивание экспортного потенциала малого бизнеса в регионе требует системного подхода, глубокого анализа проблем, создания механизма «сопровождения» экспорта по всем этапам экспортного проекта, изменения системы государственной поддержки экспорто-ориентированных предприятий в регионе со стороны содействующих государственных органов, институтов развития, включая инструменты Российского экспортного центра.

Учет этих аспектов, определяющих политику импортои экспортозамещения в РФ, обеспечит большую оперативность реагирования на изменения внешней среды, возможность минимизации негативных последствий и максимизации позитивных проявлений для национальной и региональной экономики [Императивы бизнеса, 2017. С 3].

\section{Литература}

Воронина Л. И., Кудряшова И.А. Таможенная система Российской Федерации в условиях глобализации. Кемерово: Кемеровский институт (филиал) РЭУ имени Г.В. Плеханова. 2016. С. 99.

Императивы бизнеса / Под ред. Ю.Н. Клещевского, И. А. Кудряшовой. Кемерово: Кемеровский институт (филиал) РЭУ им. Г.В. Плеханова. 2017. 280 с.

Колыханов Д.А., Балаганская Е.Н. Проблемы развития экспортного потенциала Кемеровской области в условиях бизнес-миграции // Экономика и управление инновациями. 2018. № 2. С. 27-36.

Мосейко В.О. Многофакторная оценка экспортного потенциала малых и средних предприятий региона / В.О. Мосейко, Ю.М. Азмина // Вестник Волгоградского государственного университета. 2012. № 2. С. 63-71.

О мерах по развитию системы поддержки экспорта несырьевых товаров [Эл. pecypc]. URL: http://www.rusexporter.ru/ (дата обращения: 08.08.2018).

Потапова Ю. Почему бизнес все чаще уходит из Кузбасса // Российская газета. Экономика Сибири. № 6779 (0) [Эл. peсурc]. URL: https://rg.ru/2015/09/17/ reg-sibfo/bisnes.html (дата обращения: 07.07.2018).

Статья поступила 27.08.2018.

\section{Summary}

Kudryashova I.A., Balaganskaya E. N., Voronina L.I., Russian University of Economics named after G. V. Plekhanov, Kemerovo Institute (branch), Kemerovo 


\section{Small Business and Non-Oil Exports}

The article presents the results of the study of the dynamics, commodity and geographical structure of exports of the Kemerovo region in the light of all-Russian comparisons over the past five years. Special attention is paid to the analysis of the commodity structure of non-commodity exports as a factor of qualitative improvement of the export structure and strengthening the position of the region in foreign markets. The characteristics of the non-oil export of the Kuzbass in comparison with other subjects of the Siberian Federal district. The analysis of problems, risks and factors hindering the dynamic growth of non-oil exports of Kuzbass by small and mediumsized enterprises in the context of increasing business migration to other regions of Russia. The findings suggest that the dynamics of non-oil exports of Kuzbass not only repeats the all-Russian growth trend, but also overtakes some groups of goods, while maintaining the raw orientation. Small business when entering foreign markets of non-raw materials products is experiencing significant problems and needs support.

Export potential of the region; foreign trade; non-resource non-energy exports; «environmental intensity» of regional exports; business migration of SMEs

\section{References}

Voronina L.I., Kudryashova I.A. (2016). The Customs system of the Russian Federation in the conditions of globalization. Kemerovo: Kemerovo Institute (branch) of Plekhanov Russian University of Economics. P. 99 (In Russ.).

The imperatives of the business (2017). Under the editorship of Yu. N. Kleshchevskiy, I.A. Kudryashova. Kemerovo: Kemerovo Institute (branch) of PRUE. G. V. Plekhanov. 280 p. (In Russ.).

Kolykhanov D.A., Balaganskaya E.N. (2018) Problems of development of export potential of the Kemerovo region in terms of business migration. Economics and innovations management. No. 2. Pp. 27-36. (In Russ.).

Moceyko V.O., Azmina Yu. M. (2012). Multivariate assessment of the export potential of small and medium-sized enterprises in the region Vestnik of the Volgograd state University. No. 2. P. 63-71. (In Russ.).

About measures for development of system of support of export of non-primary goods. Available at: http://www.rusexporter.ru/ (accessed 08.08.2018). (In Russ.).

Potapova Yu. Why businesses are leaving the Kuzbass. The Russian newspaper. The Economy of Siberia. No. 6779 (0). Available at: https://rg.ru/2015/09/17/regsibfo/bisnes.html (accesed 07.07.2018). (In Russ.). 